\title{
Relation between Patients with Gastric Helicobacter Pylori Infection and Dyslipidemia
}

\author{
Edson Guzmán ${ }^{1,3,5,6^{*}}$, Pedro Montes ${ }^{2,3,6}$, Eduardo Monge ${ }^{2,3,4}$ \\ ${ }^{1}$ Gastroenterology Unit of Hospital Nacional Edgardo Rebagliati Martins, Lima, Peru \\ ${ }^{2}$ Gastroenterology Unit of Hospital Daniel Alcides Carrion, Callao, Peru \\ ${ }^{3}$ Universidad Peruana de Ciencias Aplicadas (UPC) \\ ${ }^{4}$ Universidad Peruana Cayetano Heredia (UPCH) \\ ${ }^{5}$ Universidad San Martin de Porres (USMP) \\ ${ }^{6}$ Clinica Internacional Lima Peru
}

Corresponding Author: Gerly Edson Guzmán Calderon, Prol Manco II, 115- Condominio Villa Marina, Block- A, 1101-San Miguel, Lima, Perú. Tel: +5115665465/+51984767112; E-mail: edson_guzman@hotmail.com

\begin{abstract}
Objective: To evaluate the relation between gastric $H$. pylori infection and dyslipidemia.

Methods: Eligible subjects were all adult; we enrolled those patients with dyspepsia who had undergone esophagogastroduodenoscopy. They were divided in 2 groups: Case group: patients who have a histologic diagnosis of infection for H. pylori. Control group: Patients who had previous negative biopsy for H. pylori. All patients had basic serology and lipid profiles, both groups were compared.

Results: 120 patients were evaluate, 63 were female $(52.5 \%)$. Of 77 patients with dyslipidemia, 40 were positive $H$. pylori $(51.9 \%)$, and 20 of 43 non - dyslipidemic patients were positive $H$. pylori $(46.5 \%)$. Cholesterol values were $196.6 \pm 42.1$ and $191.7 \pm 29.5$; triglyceride $164.4 \pm 89.1$ and $139.2 \pm 69.1$; LDL $119.2 \pm 33.8$ and 115.9 \pm 27.4 ; VLDL $33.1 \pm 17.6$ and $29.1 \pm 15.6$, HDL: $44.4 \pm 9.1$ and $42.5 \pm 10.7$ for the positive and negative $H$. pylori groups, respectively. "p" values in all cases were not statistically significant: cholesterol $(p=0.4)$, triglycerides $(p=0.08), \operatorname{HDL}(p=0.3)$, $\operatorname{LDL}(\mathrm{p}=0.5), \operatorname{VLDL}(\mathrm{p}=0.1)$.

Conclusions: Gastric H. pylori infection does not have significant relation with the presence of dyslipidemia. The alterations of the serum lipids profiles (cholesterol, triglycerides, LDL and VLDL) are discreetly higher in the patients infected by $H$. pylori, but they are not statistically significant.
\end{abstract}

Key Words: Helicobacter pylori, Dyslipidemia, Relation

\section{What is already known about this subject?}

- Little is known about the relation between $H$. pylori and dyslipidemia.

- It is believed that there is a relation between these two entities but this belief is unsubstantiated

\section{What does this study add?}

This study finds there is little evidence that $H$. pylori infection likely contributes to an alteration in the metabolism of lipids.
Received Date: August 28, 2015

Accepted Date: October 9, 2015

Published Date: October 12, 2015

Citation: Guzman, G.E., et al. Relation between Patients with Gastric Helicobacter Pylori Infection and Dyslipidemia. (2015) J Gastrointest Disord Liver Func 1(1): 11- 14.

\section{Introduction}

Helicobacter pylori infection is an etiological factor for the development of peptic ulcer and gastric cancer ${ }^{[1,2]}$. Preliminary reports have suggested that chronic infections for $H$. pylori and other infections can be associated with atherosclerosis and vascular disease. Nevertheless, most studies have not confirmed the association between the chronic diseases and the arterial coronary disease $e^{[1,3-4]}$.

Dyslipidemia includes a group of disorders in the metabolism of cholesterol and triglycerides, which has implications in the cardiovascular system, producing pathologies as vascular coronary disease and atherosclerosis ${ }^{[5]}$.

Dyslipidemia affects half of American adults and is a major risk factor for cardiovascular disease (CVD), cardiovascular death, and all-cause mortality. Large observational studies 
have found a strong relationship between increasing levels of low-density lipoprotein (LDL) cholesterol or decreasing levels of high-density lipoprotein (HDL) cholesterol and increasing risk for coronary artery disease (CAD) events ${ }^{[6-8]}$.

In recent years, the relation between $H$. pylori infections and coronary and cardiovascular diseases has been studied. However, most prospective studies have not confirmed the association between chronic infections and coronary artery disease. H. pylori and other gram negative microorganisms, have been involved in the etiology of pathologies like vascular coronary disease and atherosclerosis, with controversial results ${ }^{[1]}$.

The objective of this study is to evaluate the relation between gastric $H$. pylori infection and dyslipidemia; given that proving a relation between $H$. pylori and cardiovascular risk factors might be an important finding to reduce the incidence of cardiovascular disease.

\section{Material and Methods}

The subjects of this study were patients admitted to the Gastroenterology Unit of the Daniel Alcides Carrion Hospital in Callao, Perú, over a one-year period. Eligible subjects were all adults (18 years or older). We prospectively enrolled the patients with dyspepsia who had undergone esophagogastroduodenoscopy. All the patients underwent physical examinations. They were divided in 2 groups: The case group included patients who had a histologic diagnosis of gastric infection for H. pylori, in a previous biopsy taken in a upper endoscopy and who also took other tests: hemogram, liver function test and serum lipids, as a complementary study. The control group included patients who previous negative biopsy for $H$. pylori and who also took the aforementioned tests.

We evaluated the following as potential confounders: BMI, smoking behavior, recent alcohol use, aspirin or nonsteroidal anti-inflammatory (NSAID) drugs use (including over-thecounter use), and comorbidities. Also excluded from the study were patients whose diagnosis of infection for H. pylori was performed with another method (e.g. test of breath, serum test, etc.), and the subjects that did not have a complete serum profile or lack of any of the mentioned tests, as well as those with history of some type of chronic pathology as cardiovascular diseases, acute myocardial infarction (AMI), unstable angina, presence of some type of neoplastic disease or diabetes mellitus. Finally, we also excluded the patients that did not agree to voluntarily take part in the study under informed consent.

Biopsy specimens stained with HE and Giemsa were used to detect $H$. pylori. The histologic degree of activity (neutrophil infiltration), inflammation (mononuclear cell infiltration), glandular atrophy, and intestinal metaplasia were classified as none, mild, moderate, and severe in accordance with the updated Sydney System.

\section{Statistical Analysis}

We performed the followed analyses: we compared the physician-assigned positive $H$. pylori group (case group) with negative $H$. pylori population (control group). We compared the demographic characteristics of every group as well as endoscopic and histological findings and serum lipids profiles.

Statistical analyses were performed using SPSS18 statistical analysis software. Unless otherwise noted, any test of a hypothesis was two-sided and the level of significance was set at $5 \%$. Potential associations between the clinical and biologic parameters were tested for by univariate analysis using Student's $t$ test or chi-square test. The results were expressed as means \pm SDs.

\section{Results}

In the present study, a total of 120 patients were evaluated; they were equally distributed in two groups: 60 patients in the case group with $H$. pylori infection and 60 patients in the group without infection (negative $H$. pylori). All the patients admitted into the present study were submitted to an upper endoscopy for the diagnosis of dyspepsia. None of the patients presented warning signs (e.g decrease weight, hemorrhage, or any other sign of organicity).

Of these 120 patients, 57 were male and 63 female, with mean age of 52.5 (range 18-82) years. The demographic characteristics were analyzed; of 63 female patients, $36(57.1 \%)$ were positive $H$. pylori, and of 57 male patients, $24(42.1 \%)$ were positive $H$. pylori, $(\mathrm{p}=0.1$; OR $=0.5$; IC 95\% $(0.2-1.1)$.

Of these 120 patients, 77 showed some type of dyslipidemia (64.1\%). Of these 77 patients with dyslipidemia, $54.5 \%$ (42 patients) were female, whereas the remaining $45.5 \%$ (37 patients) were male. (OR $=0.7$ IC 95\% (0.3-1.6). Forty of the 77 were $H$. pylori (+) $(51.9 \%)$ and 37 H. pylori (-) $(48.1 \%)$. Of the patients without dyslipidemia 20 were $H$. pylori $(+)(46.5 \%)$ and 23 were $H$. pylori $(-)(53.5 \%)$. ( $\mathrm{p}=0.5 ; \mathrm{OR}=1.2 ; \mathrm{IC}=95 \%$ $(0.5-2.6)$.

The weight ranges $(\mathrm{kg})$ were $69.7 \pm 14.4$ and $67.8 \pm$ 11.7 in the case group and the control group respectively $(\mathrm{p}=$ $0.4)$, whereas BMI $\left(\mathrm{kg} / \mathrm{m}^{2}\right)$ was $27.9 \pm 4.8$ and $26.3 \pm 5.1$ in each group respectively $(\mathrm{p}=0.07)$. Demographics features are shown in Table 1.

Table 1: Comparison of the demographics of the case and control group

\begin{tabular}{|l|c|c|c|c|}
\hline & $\begin{array}{c}\text { H. pylori } \\
(+)(\mathbf{n}=\mathbf{6 0})\end{array}$ & $\begin{array}{c}\text { H. pylori } \\
(-)(\mathbf{n}=60)\end{array}$ & p & $\begin{array}{c}\text { Signif- } \\
\text { icance }\end{array}$ \\
\hline Sex (Male / Female) & $24 / 36$ & $33 / 27$ & 0.1 & NS \\
\hline Aged (years) $(\bar{X} \pm$ SD) & $50.1 \pm 12.0$ & $50.5 \pm 14.6$ & & NS \\
\hline Hypertension (Yes $/$ No) & $4 / 56$ & $6 / 54$ & 0.5 & NS \\
\hline Smokers (Yes /No) & $1 / 59$ & $0 / 60$ & & NS \\
\hline Peso kg ( $\bar{X} \pm$ SD) & $69.7 \pm 14.4$ & $67.8 \pm 11.7$ & 0.4 & NS \\
\hline IMC kg/m $(\bar{X} \pm$ SD) & $27.9 \pm 4.8$ & $26.3 \pm 5.1$ & 0.07 & NS \\
\hline Dyslipidemia (Yes / No) & $40 / 20$ & $37 / 23$ & 0.5 & NS \\
\hline
\end{tabular}

\section{Lipids Profiles}

Results of lipid profiles are shown in Table 2. The values of cholesterol (mg/dL) were discreetly higher in the H. pylo$r i(+)$ group $(196.6 \pm 42.1 \mathrm{mg} / \mathrm{dl})$ than $H$. pylori $(-)$ group $(191.7$ $\pm 29.5 \mathrm{mg} / \mathrm{dl})$ as well as in the values of triglycerides $(\mathrm{mg} / \mathrm{dL})$, $164.4 \pm 89.1$ vs. $139.2 \pm 69.1 ; \mathrm{LDL}(\mathrm{mg} / \mathrm{dL}), 119.2 \pm 33.8$ vs. $115.9 \pm 27.4$; and VLDL $(\mathrm{mg} / \mathrm{dL}) 33.1 \pm 17.6$ vs. $29.1 \pm 15.6$. On the other hand, the values of HDL were in the H. pylori $(+)$ group than $H$. pylori $(-)$ group $(44.4 \pm 9.1$ vs. $42.5 \pm 10.7)$. None of these values showed statistically significant differences. 
Table 2: Serum lipid profiles of patients of the case and control groups

\begin{tabular}{|l|l|l|l|l|}
\hline & $\begin{array}{c}\text { H. pylori } \\
(+)(\mathbf{n}=\mathbf{6 0})\end{array}$ & $\begin{array}{c}\text { H. pylori } \\
(-)(\mathbf{n}=\mathbf{6 0})\end{array}$ & $\mathbf{p}$ & $\begin{array}{l}\text { Signif- } \\
\text { icance }\end{array}$ \\
\hline $\begin{array}{l}\text { Cholesterol mg/dl } \\
(\bar{X} \pm \text { SD) }\end{array}$ & $196.6 \pm 42.1$ & $191.7 \pm 29.5$ & 0.4 & NS \\
\hline $\begin{array}{l}\text { Triglycerides mg/dl } \\
(\bar{X} \pm \text { SD })\end{array}$ & $164.4 \pm 89.1$ & $139.2 \pm 69.1$ & 0.08 & NS \\
\hline HDL mg/dl ( $\bar{X} \pm$ SD) & $44.4 \pm 9.1$ & $42.5 \pm 10.7$ & 0.3 & NS \\
\hline LDL mg/dl $(\bar{X} \pm$ SD) & $119.2 \pm 33.8$ & $115.9 \pm 27.4$ & 0.5 & NS \\
\hline VLDL mg/dl $(\bar{X} \pm$ SD) & $33.1 \pm 17.6$ & $29.1 \pm 15.6$ & 0.1 & NS \\
\hline $\begin{array}{l}\text { Coronary Risk } \\
(\bar{X} \pm \text { SD })\end{array}$ & $4.5 \pm 1.2$ & $4.7 \pm 1.5$ & 0.3 & NS \\
\hline
\end{tabular}

\section{Endoscopical Findings}

The endoscopic distribution was determined in each group and the different findings found in the mucous gastric showed no differences between the two study groups $(\mathrm{p}=0.1)$. Five cases of gastric ulcer were found in patients with dyslipidemia, whereas it was not present in non dyslipidemic patients. Chronic and erosive gastritis was proportionally similar in each group. (See Table 3).

Table 3: Endoscopical and histological findings between patients with and without dyslipidemia

\begin{tabular}{|c|c|c|c|c|}
\hline $\begin{array}{l}\text { ENDOSCOPI- } \\
\text { CAL FINDINGS }\end{array}$ & $\begin{array}{l}\text { DYSLIPID- } \\
\text { EMIA }(\mathrm{n}=77)\end{array}$ & $\begin{array}{l}\text { NO DYSLIPID- } \\
\text { EMIA }(n=43)\end{array}$ & $\mathrm{p}$ & $\begin{array}{l}\text { Signif- } \\
\text { icance }\end{array}$ \\
\hline Cronic Gastritis & 62 & 35 & \multirow{4}{*}{0.1} & \multirow{4}{*}{ NS } \\
\hline Nodular Gastritis & 2 & 0 & & \\
\hline Erosive Gastritis & 8 & 8 & & \\
\hline Gástric Ulcer & 5 & 0 & & \\
\hline \multicolumn{5}{|c|}{ HISTOLOGICAL FINDINGS } \\
\hline Mild Gastritis & 34 & 21 & \multirow{3}{*}{0.5} & \multirow{3}{*}{ NS } \\
\hline $\begin{array}{l}\text { Moderate Gas- } \\
\text { tritis }\end{array}$ & 41 & 22 & & \\
\hline Severe Gastritis & 2 & 0 & & \\
\hline
\end{tabular}

\section{Histological Findings}

The different histological findings and severity of gastritis were determined. (See Table 3). Most were moderate and severe gastritis in the $H$. pylori (+) group (70\%), although in the H. pylori (-) group, mild gastritis was most frequent (61.6\%). $(p=0.001)$. Only two patients with dyslipidemia showed severe gastritis; $55.8 \%$ of patients with dyslipidemia had moderate gastritis and $48.8 \%$ in this group showed mild gastritis $(\mathrm{p}=0.5)$.

The coronary risk was $4.7 \pm 1.5$ in the H. pylori $(+)$ patients and $4.5 \pm 1.2$ in $H$. pylori (-) patients.

\section{Discussion}

Helicobacter pylori infection is an etiological factor for the development of peptic ulcer and gastric cancer ${ }^{[1,2]}$. Preliminary reports have suggested that the chronic infections for $H$. $p y$ lori and other infections can be associated with atherosclerosis and vascular disease $\mathrm{e}^{[1,3-4]}$. One hundred and twenty patients were investigated, which were distributed in two similar groups with the only difference being having gastric infection for $H$. pylori or not.

The demographic characteristics investigated were sex, age and the pathological precedents, all of which were similar in both groups of study. The distribution showed a light predominance in female patients in the positive $H$. pylori group (57.1\%), whereas male patients showed higher frequency of being negative $H$. pylori $(57.9 \%)$. In spite of this difference between both groups, no statistical significance was found.

The dyslipidemia includes a group of disorders in the metabolism of cholesterol and triglycerides. These disorders bring implications inside the cardiovascular system producing pathologies such as vascular coronary disease and atherosclero$\operatorname{sis}^{[5]}$. The alterations of the serum lipídic profile or dyslipidemias are classified principally under those who present hypercholesterolemia, hypertrygliceridemia, a mixed form of both, or the decrease of the cholesterol HDL. In our study of 120 patients, 77 showed some degree of dyslipidemia (64.1\%). The most important analysis of our study was the comparison of the risks of developing dyslipidemias among patients who are and are not infected by $H$. pylori.

Of these 77 patients with dyslipidemia, 40 were positive $H$. pylori (51.9\%) and 37 were negative H. pylori $(48.1 \%)$. In the group of the patients without dislipidemia, 20 of 43 patients were positive $H$. pylori $(46.5 \%)$ and 23 were negative $H$. pylori (-) $(53.5 \%)$. This information indicates that a statistically significant difference between the studied groups does not exist, in reference to acquire dyslipidemia as a consequence of this infection. Analyzing separately both groups of lipidic affectation, we observed that the risk of the patients with dislipidemia is of 0.9 .

In the study of Seung-Won Jin et $\mathrm{al}^{[1]}$, held in 2007, that investigated the association between $H$. pylori infection and coronary artery disease, the authors observed that the infection for $H$. pylori was lower in the control patients that in the patients with coronary disease ( $30.7 \%$ and $40.6 \%$ respectively), without statistical differences. In our study we found that $H$. pylori gastric infection would not have a major implication in the risk of developing a coronary disease for alteration in the lipids.

When different components of serum lipidic profile were individually analyzed, we observed that patients with gastric infection for $H$. pylori showed a higher risk of hypertrygliceridemia than with other types of dyslipidemia $(p=0.08)$, that hypercholesterolemia, HDL decrease, or increase of LDL and VLDL. Values of triglycerides in patient's positive $H$. $p y$ lori were $164.4 \pm 89.1 \mathrm{mg} / \mathrm{dl}$ and negative $H$. pylori were 139.2 $\pm 69.1 \mathrm{mg} / \mathrm{dl}$. None of the different components of the lipidic profile showed a difference between the patients with positive $H$. pylori and negative $H$. pylori. Nevertheless, it is important to say that the patients $H$. pylori $(+)$ showed higher hypercholesterolemia, hypertrygliceridemia, values higher of cholesterol LDL and VLDL. Values of cholesterol were 196.6 \pm 42.1 and $191.7 \pm 29.5$; triglycerides: $164.4 \pm 89.1$ and $139.2 \pm 69.1$; LDL: $119.2 \pm 33.8$ and $115.9 \pm 27.4$ and VLDL: $33.1 \pm 17.6$ and $29.1 \pm$ 15.6; for the groups of positive $H$. pylori and negative $H$. pylori respectively.

Niemelä et $\mathrm{al}^{[9]}$ in 1996 , showed that $64 \%$ of the patients with arterial coronary disease and $53 \%$ of the control patients were positive for $H$. pylori. Among the control patients, those that were positive for $H$. pylori had higher concentrations of triglycerides with a statistically significant difference $(\mathrm{p}=$ 0.03 ) and in those who were negative for $H$. pylori, these concentrations were similar and without statistically significant dif- 
ferences.

An interesting piece of information to analyze is that, as it is well-known that HDL values lower than $40 \mathrm{mg} / \mathrm{dl}$ are a source of major coronary risk, we found in our study that HDL values are discreetly higher in patients positive for $H$. pylori than patients negative for $H$. pylori $(44.4 \pm 9.1$ and $42.5 \pm 10.7$ respectively). Nevertheless, this is not a major source of coronary risk. This differs from the study of Yi SJ, in his study dyslipidemia and $H$. pylori in gastric xantomatosis ${ }^{[10]}$. In this study where prevalence of $H$. pylori infection was similar in the patients with xantomatosis and the controls, was observed that in the first group the level of cholesterol HDL was lower than in the control group ( $48.8 \pm 12.3$ vs. $62.9 \pm 40.5 ; \mathrm{p}=0.028)$, and the values of cholesterol LDL were much higher in the patients with gastric xantomatosis than in the control group $(112.9 \pm 29.9$ vs. $95.9 \pm 22.4, p=0.032)$. Values of cholesterol in this study did not show significant differences $(188.7 \pm 32.8$ vs. $189.2 \pm 30.9)$.

Niemelä et al ${ }^{[9]}$, concluded that $H$. pylori was an independent risk factor for arterial coronary disease and that $H$. pylori can modify and increase the serum concentrations of lipids and therefore increase the appearance of a coronary disease. In our study, we can affirm that a not significant increase exists statistically in the patients who are positive $H$. pylori.

According to the study conducted by Gulden et $\mathrm{al}^{[11]}$, in 2009, the infection for $H$. pylori can stimulate the atherogénesis for indirect effects, such as a systemic inflammation or autoimmune reactions, due to the fact that the $H$. pylori is rapidly eliminated in the systemic traffic before reaching the wall of blood vessels $^{[11-14]}$.

We concluded that coronary risk is discreetly higher in the patients who present infection for $H$. pylori, nevertheless the difference is not statistically significant $(\mathrm{p}=0.3)$.

Some characteristics of the patients can interfere in the correct interpretation of the relation that can exist between the gastric infection for $H$. pylori and the dyslipidemia, such as the coexistence of diabetes mellitus or a metabolic syndrome. This is the reason why these were excluded as criteria of incorporation in our study because it would influence the result.

Some other factors were studied that did not show implications in the results, for example: $8.3 \%$ of the patients $(10$ of the 120) had the diagnosis of arterial hypertension, the difference between both groups of study (positive and negative $H$. pylori) was not significant; 4 of 60 patients positive for $H$. pylori $(6.6 \%)$ were hypertensive, whereas 6 of 60 patients negative for H. pylori $(10 \%)$ had this pathology. Only one of the patients in this study mentioned that he was a smoker; nevertheless this data point did not alter the results of our study. The BMI and the nutritional condition also did not show differences when the frequencies were compared between the groups of study (positive and negative $H$. pylori).

\section{Conclusion}

In conclusion, the gastric $H$. pylori infection does not have a significant relation with the presence of dyslipidemia. The alterations of the serum lipids profiles (cholesterol, triglycerides, LDL and VLDL) are discreetly higher in the patients infected by H. pylori, but they are not statistically significant. Future studies are needed to evaluate and find a relation between $H$. pylori and coronary diseases.

Disclosure Statement: The authors have nothing to disclose.

\section{References}

1. Jin, S.W., Her, S.H., Lee, J.M., et al. The Association between current Helicobacter pylori infection and coronary artery disease. (2007) Korean J Intern Med 22(3): 152- 6.

2. Huang, J.Q., Zheng, G.F., Sumanac, K.., et al. Meta-analysis of the relationship between CagA seropositivity and gastric cancer. (2003) Gastroenterology 125(6) : 1636- 44.

3. Mendall, M.A., Goggin, P.M., Molineaux, N., et al. Relation of Helicobacter pylori infection and coronary heart disease. (1994) Br Heart J 71(5): 437- 9.

4. Danesh, J., Collins, R., Peto, R. Chronic infections and coronary heart disease: is there a link? (1997) Lancet 350(9075): 430- 6.

5. Durrington, P. Dyslipidaemia. (2003) Lancet 362(9385): 717-31.

6. Anderson, K.M., Castelli, W.P., Levy, D. Cholesterol and mortality. 30 years of follow-up from the Framingham study. (1987) JAMA 257(16): 2176- 80

7. Goldbourt, U., Yaari, S. Cholesterol and coronary heart disease mortality. A 23-year follow-up study of 9902 men in Israel. (1990) Arteriosclerosis 1094): 512-9.

8. Kopin, L., Lowenstein, C. In the clinic. Dyslipidemia. (2010) Ann Intern Med 153(3): ITC21

9. Niemelä, S., Karttunen, T., Korhonen, T., et al. Could Helicobacter pylori infection increase the risk of coronary heart disease by modifying serum lipid concentrations?. (1996) Heart 75(6): 573- 5.

10. Yi, S.J. Dyslipidemia and H pylori in gastric xantomatosis. (2007) World J Gastroenterol 13(34): 4598- 601.

11. Tamer, G.S., Tengiz, I., Ercan, E., et al. Helicobacter pylori seropositivity in patients with acute coronary syndromes. (2009) Dig Dis Sci 54(6): 1253- 1256.

12. Mayr, M., Kiechl, S., Willeit, J., et al. Infections, immunity, and atherosclerosis: associations of antibodies to Chlamydia pneumoniae, Helicobacter pylori, and cytomegalovirus with immune reactions to heat-shock protein 60 and carotid or femoral atherosclerosis. (2000) Circulation. 102 (8): 833-839.

13. Jia, E.Z., Zhao, F.J., Hao, B., et al. Helicobacter pylori infection is associated with decreased serum levels of high density lipoprotein, but not with the severity of coronary atherosclerosis. (2009) Lipids in Health and Disease. 59 (8): $1-7$

14. Pellicano, R., Mladenova, I., Broutet, N., et al. Is there an association between Helicobacter pylori infection and coronary heart disease? (1999) Eur J Epidemiol 15(7): 611- 9. 